\title{
Professional Development within Bachelors Programs: Addressing the Needs of a Diverse Student Population Entering Health Care
}

\author{
Dina Batlivala Tresselt* \\ College of Health Sciences, Rush University, 600 South Paulina St., Suite 1001 AAC \\ Email: dina_batlivala@rush.edu \\ Mary Jo Guglielmo \\ College of Health Sciences, Rush University, 600 South Paulina St., Suite 1001 AAC \\ Email: mary_j_guglielmo@rush.edu \\ Brinda Desai Bradaric \\ College of Health Sciences, Rush University, 600 South Paulina St., Suite 1001 AAC \\ Email: brinda_d_bradaric@rush.edu
}

\begin{abstract}
Following graduation from an undergraduate institution, students have the perception that they have the skills necessary to be successful in the workforce and/or graduate studies, however employers and professors do not agree. Professional development during undergraduate studies may help bridge the gap between student and employer/professor perceptions. Based on the discrepancies in post-graduation readiness perception and the number underrepresented minorities in health care and post-graduate studies, the Bachelor of Health Sciences (BSHS) program at Rush University established a professional development program with the goal of providing students seminars that enhance their professional and social skills. Offering a professional development program ensures that students gain and maintain relevant academic and non-academic competencies that will support them in their academics and prepare them for their professional careers, which can be particularly effective for students from diverse racial and ethnic backgrounds and students studying within a diverse cohort. Surveys were conducted to determine the perception of effective and usefulness of each seminar as well as utility of the tools provided to students in each seminar during their academic and professional career. Overall, the professional development seminar series improved student utilization and application of tools provided at each seminar to improve student perception of readiness and gain confidence in their academic and professional development. The seminars also positively influenced formation of diverse relationships, as many of the tools provided were used in personal and social situations. A dynamic professional development program can provide useful tools and improve readiness perception in a diverse student population within an undergraduate program. As graduate programs and companies across the country continue to expand their diversity initiatives, professional development during undergraduate studies becomes even more relevant as it addresses their ability to be successful and resilient.
\end{abstract}

Keywords: Professional Development, Diversity, Bachelors, Health Care

DOI: $10.7176 / \mathrm{JEP} / 11-29-02$

Publication date:October $31^{\text {st }} 2020$

\section{Introduction}

As undergraduates move into graduate studies and the workplace, professors and employers acknowledge the fact that students are lacking in professional behavior standards (McGraw-Hill, 2018). After attending four years of undergraduate schooling, students have the perception that they are ready for the world beyond academics, applying their gained knowledge to their field of choice. However, employers do not always agree. According to a 2018 McGraw-Hill Education Future Workforce Survey (Workforce Survey Table).

Professional development is important because it helps bridge the gap between student and employer perceptions. Furthermore, it creates more well-rounded students. Professional development can help in academic performance by improving group work, oral presentation, and overall dynamics in the classroom (Kenney, 1997). Students' ability to become compassionate health care providers, who are ready to serve a diverse patient population is also encouraged by attainment of professional development competencies. However, research on how to develop and implement professional development for diverse students in a Bachelor of Science (BS) undergraduate curriculum is lacking. Further, assessment of attainment of non-academic competencies prior to entering the workplace is minimal.

The racial and ethnic diversity of the United States continues to increase (Shrestha et al., 2011). Underrepresented minority in health care (URM), is currently defined as Black/African American, Hispanic/Latin, Native American, and Hawaiian/Pacific Islander (Shrestha et al., 2011). According to the July 2019 United States 
Census Bureau reports, $18.3 \%$ of the country is Hispanic/Latin, $13.4 \%$ is Black/African American, $1.3 \%$ is Native American, and .2\% is Hawaiian/Pacific Islander. From 2000-2016 the Hispanic/Latin population increased 2\%, the Black/African American population increased 1.2\%, the Native American population increased 1.4\%, and the Hawaiian/Pacific Islander population increased 2.1\%, bringing the total United States self-reported URM diverse population to 112.5 million. These increases in population diversity is not reflected in those who have a bachelor's and/or graduate degrees. This increased racial and ethnic diversity is also not reflected in the number of health care practitioners in the country. For example, according to the National Center for Education Statistics, in 2017, approximately 6.7 million undergraduates were minorities compared to 10 million whites and Asian. Scholars suggest that expanding the diversity of health care professionals can support culturally competent care and facilitate access to care for traditionally underserved, minority populations (Betancourt et al., 2002).

Further, the disproportion of whites within undergraduate and graduate degrees also does not reflect the patient population that most urban health systems serve. Thus, there are initiatives across the country to increase diversity within all health care teams, including within BS in health sciences programs. In 2019, Senators Bob Menendez (D-NJ), John Boozman (R-AR), and Chuck Schumer (D-NY) introduced the Resident Physician Shortage Reduction Act of 2019. This legislation was designed to strengthen the health care system and address the physician shortage. According to the Association of American Medical Colleges (2019), "the legislation also requires the Comptroller General to conduct a study on strategies for increasing health professional workforce diversity." In order to increase diversity in a cohort, one must consider the support that is needed for diverse students, not only to keep them in the program, but to help them excel. It is important to note that diversity can also refer to sex and age along with race and ethnicity. Professional development with an emphasis on diversity and inclusion of all sexes, race, ethnicity and age, must be considered a part of any well-rounded BS undergraduate curriculum.

Based on the discrepancies in post-graduation readiness perception and number URM in health care and postgraduate studies, the Bachelor of Health Sciences (BSHS) program at Rush University established a professional development program in 2016 with the goal of providing a non-formal arena in which students could enhance their professional and social skills. This need was further evidenced by the high proportion of minority students $(68 \%)$ having matriculated into the BSHS program. Defined by the BSHS program, professional development is the process of improving and increasing the capabilities of the student population through education, and training opportunities. Offering a professional development program ensures that students gain and maintain relevant academic and non-academic competencies that will support them in their academics and prepare them for their professional careers. Not only is professional development relevant for all bachelor's students, it can be particularly effective for students from diverse racial and ethnic backgrounds and students studying within a diverse cohort. Not all students have developed these skills within a family setting and are relying on the traditional setting of academics, in order to do so.

The BSHS program has built and executed a professional development program that helps develop wellrounded students with diversity and inclusion competencies. The BSHS program also focuses on building a diverse health care workforce, which will in turn reflect the patient population that the Rush Systems serves. This study highlights how the professional development program was developed, implemented, and used by students during their academic and professional career. The study outcomes emphasize the importance of a dynamic program that can address the changing student population within an undergraduate program.

\section{Methods}

Cohort Classification: For each cohort that experienced the professional development program seminars, diversity parameters such as socioeconomic background, age of entry into the program, and self-reported race and ethnicity were collected. Following graduation from the BSHS program, additional parameters such as first-generation higher education graduate, occupation, and graduate level education, was collected.

Mapping the Curriculum: Mapping required the program to define non-academic based competencies such as communication (verbal and non-verbal), ethics, collaboration/teamwork, critical thinking, problem solving, cultural competence, inclusion, leadership, time management, study skills, note taking skills, technical skills, and social development. These competencies were then mapped to courses offered in the BSHS program to determine which were obtained through formal classroom objectives. The competencies were further assessed as to whether they were introduced, reinforced, or mastered in the classroom. If a course met more than one competency, it was counted more than once. Competencies that were not obtained or mastered in the classroom were identified, and seminars were created to address the lack of incomplete formal classroom teachings.

Seminars: Seminars were scheduled during lunch hour to help facilitate student attendance. Faculty and staff were also present at seminars to help encourage attendance. Seminars took place throughout the academic year (September - April). Attendance was taken at each seminar.

Pre-surveys were conducted prior to the seminar to gauge the state of student development. The pre-survey results were also used by the presenter to focus the seminar. The following questions are examples for note taking 
and time management sessions, which were utilized in the pre-survey:

1. List at least two tools/strategies that you currently use when (taking notes/managing your time) for class.

2. The (note taking/time management) skills that I am currently using are efficient in helping me study. (Strongly agree, agree, neutral, disagree, strongly disagree)

3. Do you have any struggles with (note taking/time management)? (Y/N) If yes, please explain

Post-surveys were conducted immediately following each seminar in order to evaluate the presenter's effectiveness and the relevance of the seminar. The following questions/prompts are examples for note taking and time management sessions that were utilized in the post-survey:

1. Did this workshop address your current struggles regarding (note taking/time management? $(\mathrm{Y} / \mathrm{N})$

2. I have a better understanding of how to improve my (note taking/time management) skills after attending this workshop (Strongly agree, agree, neutral, disagree, strongly disagree)

3. List at least two ideas/skills you have learned from this workshop that you plan to put into practice.

4. What is something that you hoped would be addressed in this workshop that was not covered?

The evaluations were also used to help determine changes in seminar or presenter for the following year.

An end of the semester survey was completed by students in order to gauge knowledge attained and maintained from each seminar through the semester. An end of the year survey was conducted in order to determine how the professional development topics were applied, used, and maintained throughout the entire academic year. An alumni survey was also sent to determine the overall use of tools/ideas provided in attended seminars on graduate education and/or career following undergraduate graduation. Data for the end of the year, end of the semester and alumni survey are expressed as average percentage \pm SEM. All surveys were completed anonymously, except for the alumni survey.

\section{Results}

Since its inception in Fall of 2013, the BSHS program, by design, has had small, diverse cohorts of roughly 15 students each, ranging in age from 18-52 (Table 1). The average age is late to mid-twenties, which is higher than the average age of bachelor students in a 4-year institution. Interestingly, every year there were more females in the program than males. More than $50 \%$ of each cohort self-reported as underrepresented minority in health care (URM), (Table 1). The range of age and race/ethnicity of students within each cohort is suggestive of the diversity of each cohort. Most of the students have multiple responsibilities outside of the classroom, including work, and family obligations, which was taken into consideration when planning their course of study in the program and ability to attend professional development seminars.

The program reviewed the overall curriculum. Two groups of competencies were identified: educational skills and development (Table 2), and individual and social competencies (Table 3). Many competencies were covered in the classroom, through multiple courses, at the introduction, reinforced and mastered level. However not all competencies were developed within the classroom setting, including time management, and classroom skills, as well as individual development, such as assertiveness, resilience, and balance. Leadership and ethics were included in formal classroom teaching, but needed further reinforcement with special emphasis on diversity and inclusion. Cultural competency and inclusion are weaved into a number of courses at the reinforced level, based on personal communication with students, and other health science faculty, and in class assignments. However, seminars were developed to separate the topic from the classroom setting, to allow for more effective conversations (Table 4).

During the first two academic years, the number of seminars $(n=5)$ was low due to planning and findings speakers. However, in 2018, the number of seminars doubled (Table 5). Due to part time schedules and work, approximately half of the students in the program, both $1^{\text {st }}$ year and $2^{\text {nd }}$ year students, attended the seminars. More females in the cohort attended the seminars, then the males. Of those that attended, more than $50 \%$ were URMs (Table 5).

From the post survey, each survey had the question: After this seminar, I had a clearer/better understanding of how to (blank based on seminar topic). Throughout the past three years of the professional development program, approximately $60 \%$ of the students who attended the seminar gained a better understanding of the topic (Tables 68). The percentages are slightly different for each cohort, even though the speakers for the repeated seminars are the same, suggestive of the changing diversity (age, race/ethnicity, sex) of the students each year. Even with the different diversity make-up of the cohorts, all of the students felt as though they gained something from each seminar attended. In 2018-2019, for the inclusion and bias, note taking and communication, the question was changed slightly to gain an understanding of how specific parameters were learned (Table 8). In the inclusion and bias seminar, more students understood the meaning of bias than inclusion. In the note taking seminar, students had a slightly better understanding of how to take notes after class than during. In the communication seminar, students had a better understanding of how to speak with peers than professors. Knowing this information can help guide subsequent seminars that have additional focus on inclusion, note taking during class, and speaking with professors. 
The end of the semester and end of the year for the 2018-2019 academic year questions highlight how the students applied the workshops toward academic and professional growth. In the 2018 fall semester seminars, $29 \pm 1.6 \%$ students used the tools provided in each seminar daily, while $46 \pm 5 \%$ of students used the tools on a weekly basis. Interestingly, by the end of the year, $41 \pm 1.4 \%$ of students used the tools daily, increasing the daily use of learned tools in the previous semester by $12 \%$. Since more students were using these skills daily, the weekly use decreased $(30 \pm 7.5 \%)$.

To gain a better understanding of the where the tools were being implemented, the end of the semester and end of the year survey asked the question: where were the practices implemented? Students were asked to check all that applied: tools were implemented in all classes, only in classes he/she was struggling in, or in his/her personal life. In the 2018 fall end of the semester seminar series survey, $64 \pm 6 \%$ of students used the tools attained from the seminars in all classes and $25 \pm 3 \%$ applied tools in only classes he/she was struggling in throughout the semester. Not surprising, the most utilized seminars, where tools provided were used in all classes, were note taking and study skills. Time and stress management tools, though utilized in course work, were more regularly used in the student's personal life (38\% versus $13.5 \%$ for note taking and study skills). To determine how these practices changed over the course of the year, students were asked the same question for the same seminars at the end of the year. Interestingly, only $51 \pm 8 \%$ used the previous semester's seminar tools in all classes, showing a downward trend in use of tools attained from fall semester. However, there was an increase in the percentage of students $(30 \pm 6 \%)$ using the tools in courses in which they were struggling, suggesting that the students beginning to understand how the tools help their academic performance. Time management $(63 \%)$ tools were more used in student's personal life than any other tools attained (14\%). At the end of the semester, $82 \pm 5 \%$ of students said that the tools that were provided in each of the seminars helped him/her improve his/her grade in at least one course or reduce study time to achieve the same grade. By the end of the year, $63 \pm 4 \%$ of students felt that the tools from the fall semester help improve his/her personal and/or social interactions.

In order to determine the impact of the tools gained from the professional development seminar series, an alumni survey was conducted. Graduate level education and personal perception were used to assess the impact of the professional development program. Using perception of students, post-graduation, allows for students to reflect and practically apply knowledge, allowing for a better assessment of usefulness self-reflection of the professional development program. Thirty alumni replied, making the response rate $68 \%$. Of those 30 responses, 18 participated in the professional development seminars during their time in the program. Sixty-five percent of those who attended the seminars were URM and the majority of URM students were first generation graduate from higher education. Overall, URM students found the professional development helped them prepare in several arenas, including interviews, personal and professional development, and graduate academics (Table 9). In support, 58\% of the students who went through the professional development program were accepted, and in some cases obtained, graduate education, including but not limited to MS in HSM, MS in Nursing, MS in Health Informatics, MS in Physician Assistant Studies, Doctorate in Occupational therapy, and Medical Doctorate. Of those, 32\% were URM.

Sixteen of the respondents $(89 \%)$ either strongly agreed or agreed that prior to the professional development series they needed additional help with competencies, such as time management and study skills. Of the $89 \%$ who identified their prior need for help with competencies, 69\% were URM students. These URM students, also felt that during the professional development series they gained and used competencies and realize how enhanced competencies have and continue to improve multiple areas of their lives. In an open ended question asking how the professional development seminar series enriched their experience at Rush, students expressed gaining comfort and confidence, gaining insight and tools for current and future academics; and a it was a great way to get skills that may have been missed in other educational settings.

\section{Discussion}

Overall, this study developed and implemented a professional development seminar series that positively influenced student utilization and application of tools provided at each seminar to help improve student perception of readiness. Students were also more confident in their academic and professional development and thus obtained graduate degrees and/or employment following completion of the BSHS and professional development program. The seminars also positively influenced formation of diverse relationships, as many of the tools provided were also used in the personal and social situations. Research shows that students entering medical and nursing higher education lack or need improvements on professional behaviors (McGraw-Hill, 2018), most likely because the lack in competencies is not addressed in a BS curriculum prior to entering these health care professional studies. The BSHS professional development program provided students tools for academic performance and professional and personal success, helping to close the gap between student and employer/professor readiness perception.

The cohorts within the BSHS program are diverse in age and race. The range in age reflects that cohorts are composed of individuals who are young and fresh out of high school, as well as individuals who have work or life experiences. More than $50 \%$ of each cohort self-reported as an URM. The diversity of these parameters can bring a variety of opinions and viewpoints into the classroom, but also anger, and even misunderstanding, because of 
the generation and experience gap. Without the professional development program, students may not have learned how to work as a team, handle conflict, or to respect differing opinions and viewpoints, which are essential components of becoming a health care professional. Additionally, without having meaningful conversations regarding diversity, students would not gain the confidence and social skills needed to participate in class or be more assertive in an interview, etc. A URM alum stated, "It helped me gain confidence in several areas I've always had trouble with, such as being intimidated because English is my second language and I've very selfaware that I mispronounce words." This alum reflected how the seminars helped her "prepare at all times to engage and manage conversations at a more professional level." Another alum stated that the seminars provided, "insight into a professional role that I wasn't prepared for otherwise. I am more confident."

URM students face disproportionately more barriers, especially regarding the completion of any higher education. Students face academic challenges if they have fewer resources, less college-prep coursework, or no college knowledge passed down from family members. These students rely on support services, including counseling, tutoring, mentoring, and professional development training. Non-URM students may be unaware of challenges they will face in a diverse workplace or graduate setting. Promoting professional development provides support, reduces biases, enhances institutional diversity and improves cultural awareness (Odom, et al., 2007). Student support services, including professional development programs are associated with improved academic outcomes (DOE, 2016). The percentage of use of tools provided in the seminars, whether utilized daily or weekly, in all classes or in classes in which a student was struggling, suggests that many students did not know how to use the support and tools until the completion of the seminar. Once students were taught how to utilize and apply the tools, $82 \pm 5 \%$ of students said the seminars helped him/her improve his/her grade in at least one course or reduce study time to achieve the same grade. An alum reflected that "I still reference back to some of the techniques for studying and preventing procrastination. I believe I am a better student and researcher as a result of the skills I acquired" during the professional development program seminars.

As students advanced in academics, from junior to senior year, students used the tools more often as suggested by the $12 \%$ increase in daily use of years from the end of the semester to the end of the year. The seminars helped the students become more aware of the need for additional tools, especially as the courses become more difficult. Furthermore, the tools obtained from the time management and stress management seminars were used more in personal life than academic life. This supports the idea that a student's responsibilities outside of school, such as work, family, and health can significantly impact academic performance. A student commented that the professional development seminars, "helped me gain tools that allowed me to balance my school and personal life, equipped me with time organizational skills, and different way to study efficiently." They see the value in using these tools to help manage life, so that academics can be positively influenced. Overall, the tools learned in the time management seminar had the greatest impact on students throughout the year, suggesting that this is the largest barrier students face. It must be a seminar that is provided in the program development program every year.

With a national push to increase the representation of both minorities and females within sciences, it is imperative that programs develop additional support for students outside of the classroom experience. Data collected from this study suggests that professional development seminars are important and can influence a student's success within the program as well as when they continue into their graduate studies and health care careers. As reflected in the alumni survey data, though all students gained competencies that were used for employment and/or graduate academics, URM students found the experience rewarding and needed. An URM student added, "At the time I may not have realized the benefits from having those sessions. But after reflection of my overall experience I would say that they really did help shape my future in graduate school." The professional development program is not a set of seminars that only benefit URMs, but a non-URM alum said that the "series not only provided helpful skills for school, but for post-graduation life experiences as well." According to the alumni survey, students felt better prepared for these health care roles in part due to their professional development experiences.

The program has continued to make changes and improvements to the professional development series, primarily based on student feedback and faculty interaction during seminars. In 2019-2020 the program increased the number of speakers from diverse backgrounds who shared their unique and non-traditional career paths. Due to the changing student population and the world environment, the program increased the number of social development seminars focusing on coping skills. Based on student feedback and as the data shown in this study, the program maintained many seminars, including stress management, time management, and note taking. Due to the importance of the professional development series, the BSHS program hired a student advisor/career development coordinator. This role continues to support the students' needs and enhance professional development program to allow for all students, URM and non-URM, to gain the needed competencies for success in academics and a health care careers.

Based on the analysis and reflection of the results presented in this paper, the BSHS program also determined that first year (juniors) and second year (seniors) are in different places within their academic careers, therefore the program developed individualized plans of professional development seminars, based on year in school. The 
first-year seminars focus on academic development whereas the second-year seminars focus on post-graduation professional development. Personal and social development is weaved throughout the two years of seminars. Future research could include how the expansion of the professional development program has directly impacted student outcomes within courses in the BSHS program as well as employment following graduation and graduate studies. Student outcomes can dictate the professional development seminars from year to year, reflecting the diversity of the program. It would relevant to asses, as the diversity within the program expands, additional seminar topics that need to be included: cultural competencies, health equity, and the disparities surrounding a pandemic, to name a few.

The professional development program helped students, develop professional, personal, and social competencies, in part due to the dynamic nature of the seminars and the leadership of the program to acknowledge and adapt to the student population's changing needs and changing diversity. As the professional development program continues to improve, it will be important to consider expanding the definitions of diversity beyond selfidentified URMs to include gender, disability, and even age (Bulk, et al., 2019). This professional development program allows for the gap between student and employer perception of readiness within in a health care field to grow smaller, as more well-rounded, diverse students prepare for their health care professions.

\section{References}

Association of American Medical Colleges. "The Resident Physician Shortage Reduction Act of 2019 (S. 348) Section-by-Section Summary." black.global.ssl.fastly.net/production/media/filer_public/5d/cf/5dcf91a7-b0c0-41fb-9dc8$8910503 \mathrm{cbad} 3 / \mathrm{dgme}$ - the resident physician shortage reduction act of $2019 \mathrm{~s}$ section - 20190206.pdf

Betancourt, J. R., Green, A. R., \& Carrillo, J. E. 2002. "Cultural Competence in Health Care: Emerging Frameworks and Practical Approaches." New York: The Commonwealth Fund.

Fan, A. P., Chen, C. H., Su, T. P., Shih, W. J., Lee, C. H., \& Hou, S. M. 2007. "The Association Between Parental Socioeconomic Status (SES) and Medical Students' Personal and Professional Development." Annals of the Academy of Medicine, Singapore, 36(9), 735-742. https://pubmed.ncbi.nlm.nih.gov/17925981/

Bulk, L. Y., Tikhonova, J., Gagnon, J. M., Battalova, A., Mayer, Y., Krupa, T., . . Jarus, T. (2019). Disabled healthcare professionals' diverse, embodied, and socially embedded experiences. Advances in Health Sciences Education, 25(1), 111-129. doi:10.1007/s10459-019-09912-6

Kennedy, M. 1997. "Defining Optimal Knowledge for Teaching Science and Mathematics." (Research Monograph 10). Madison, WI: National Institute for Science Education, University of Wisconsin.

Lown, N., Davies, I., Cordingley, L., Bundy, C., \& Braidman. 2009. "Development of a Method to Investigate Medical Students' Perceptions of Their Personal and Professional Development." Advances in Health Sciences Education, 14, 475-486. https://link.springer.com/article/10.1007/s10459-008-9130-6

McGraw-Hill. (2018). 2018 "McGraw-Hill Future Workforce Survey." https://www.mheducation.com/futureworkforce

National Center for Education Statistics n.d. "The Condition of Education."https://nces.ed.gov/programs/coe/indicator_cha.asp

Northrup-Snyder, K., Menkens, R., Dean, M. 2017. "Student Competency Perceptions From Associate Degree to Bachelor Degree Completion." Journal of Nursing Education, 56(10), 581-590. doi: 10.3928/0148483420170918-02

Odom, K. L., Roberts, L. M., Johnson, R. L., \& Cooper, L.A. 2007. "Exploring Obstacles to and Opportunities for Professional Success Among Ethnic Minority Medical Students." Academic Medicine, 82(2), 146-153. doi: 10.1097/acm.0b013e31802d8f2c

Shrestha, L. B. \& Heisler, E. J. 2011, March 31. "The Changing Demographic Profile of the United States” (Report No. RL32701). Congressional Research Service. https://fas.org/sgp/crs/misc/RL32701.pdf

U.S. Census Bureau QuickFacts: United States. n.d. https:/www.census.gov/quickfacts/fact/table/US/PST045219

U.S. Department of Education. 2016. "Advancing Diversity and Inclusion in Higher Education: Key Data Highlights Focusing on Race and Ethnicity and Promising Practices." https://www2.ed.gov/rschstat/research/pubs/advancing-diversity-inclusion.pdf

Wallace, T. L., Kelcey, B., \& Ruzek, E. "What Can Student Perception Surveys Tell Us About Teaching? Empirically Testing the Underlying Structure of the Tripod Student Perception Survey." Sage Journals, 53(6), 1834-1868. https://journals. sagepub.com/doi/10.3102/0002831216671864

Weiss, D., Hajjar, E., Giordano, C., \& Joseph, A. 2016. "Student Perception of Academic and Professional Development During an Introductory Service-learning Experience." Science Direct, 8(6), 833-839. https://www.sciencedirect.com/science/article/ abs/pii/S1877129715301659 
Notes/Tables

Workforce Survey Table

Workforce Survey Table

\begin{tabular}{lcc}
\hline & $\begin{array}{c}\text { Student } \\
\text { (\% agree) }\end{array}$ & $\begin{array}{c}\text { Employers } \\
\text { (\% agree) }\end{array}$ \\
\hline Professionalism and work ethic are proficient & 77 & 43 \\
Leadership skills are proficient & 61 & 33 \\
Communication skills are proficient & 61 & 42 \\
Career management skills are proficient & 53 & 18 \\
Global and intercultural fluency is proficient & 40 & 20 \\
\hline
\end{tabular}

Table 1

General Cohort Demographics

\begin{tabular}{lcccc}
\hline & 2015 & 2016 Cohort & 2017 Cohort & 2018 Cohort \\
& Cohort & & & \\
\hline Number of students & 12 & 15 & 13 & 23 \\
Matriculation age (Mean \pm SEM) & $24.5 \pm 1.1$ & $29 \pm 2.2$ & $24.5 \pm 1.1$ & $29.3 \pm 1.9$ \\
Age range upon matriculation & $20-32$ & $19-45$ & $18-32$ & $20-51$ \\
Gender Ratio (M:F) & $1: 3$ & $2: 3$ & $6: 7$ & $4: 19$ \\
Ethnicity (\%) & 0.1 & 0.1 & 0 & 0 \\
Native American & 0 & 0 & 0 & 0 \\
Hawaiian/Pacific Islander & 0.1 & 26.6 & 0.1 & 30.4 \\
Black/African American & 50 & 40 & 54 & 26 \\
Hispanic/Latino & 25 & 46.6 & 23.1 & 48 \\
White/Caucasian & 25 & 0 & 38.5 & 0 \\
Asian & & & & 0 \\
\hline
\end{tabular}

Table 2

Educational skills and development competencies

\begin{tabular}{lccc}
\hline & \multicolumn{2}{c}{ Number of classes in 2-year curriculum } \\
\cline { 2 - 4 } & Introduced & Reinforced & Mastered \\
\hline Fundamental knowledge of science and health practice & 1 & 6 & 9 \\
Time management & 0 & 0 & 0 \\
Communication & 1 & 6 & 3 \\
Collaborative/teamwork & 3 & 3 & 3 \\
Critical \& Creative thinking & 4 & 9 & 4 \\
Quantitative reasoning & 3 & 2 & 3 \\
Problem-solving & 4 & 4 & 3 \\
Classroom skills (study, test taking, note taking, computer) & 0 & 0 & 0 \\
\hline
\end{tabular}

Table 3

Individual and Social Development competencies

\begin{tabular}{lccc}
\hline & \multicolumn{2}{c}{ Number of classes in 2-year curriculum } \\
\cline { 2 - 4 } & Introduced & Reinforced & Mastered \\
\hline Ethics and Values & 1 & 0 & 1 \\
Leadership & 1 & 1 & 1 \\
Cultural competence and inclusion & 1 & 7 & 2 \\
Sense of self/self-knowledge & 1 & 0 & 2 \\
Assertiveness/confidence & 0 & 0 & 0 \\
Resilience & 0 & 0 & 0 \\
Balance & 0 & 0 & 0 \\
Conflict resolution & 0 & 0 & 0 \\
Accountability & 0 & 0 & 0 \\
\hline
\end{tabular}


Table 4

Professional development program seminars

\begin{tabular}{ll}
\hline \multicolumn{1}{c}{ Seminar Titles } & \multicolumn{1}{c}{ Times } \\
\hline Stress Management & Fall 2016, Fall 2018 \\
Time Management & Spring 2017, Fall 2017, Fall 2018 \\
Note Taking & Spring 2017, Spring 2018, Fall 2018 \\
Leadership Skills & Spring 2017, Spring 2018 \\
Career Path of an Individual & Spring 2017 \\
Study Skills & Fall 2017, Fall 2018 \\
Inclusion and Bias Panel & Fall 2017 \\
Managing Your Finances & Spring 2019 \\
Unconscious Bias & Spring 2019 \\
\hline
\end{tabular}

Table 5

Student demographics within all seminars

\begin{tabular}{lccc}
\hline & \multicolumn{3}{c}{ Academic year } \\
\cline { 2 - 4 } & $2016-2017$ & $2017-2018$ & $2018-2019$ \\
\hline Number of seminars & 5 & 5 & 12 \\
Number of students attended/seminar (Mean \pm SEM) & $12 \pm 1.7$ & $10.2 \pm 1.5$ & $16.2 \pm 1.1$ \\
Number of URM/seminar (Mean \pm SEM) & $8.4 \pm 1.1$ & $8 \pm 1.2$ & $9.8 \pm 0.6$ \\
Number of females/seminar (Mean \pm SEM) & $8.6 \pm 1.5$ & $5.4 \pm 1.8$ & $12.2 \pm 0.7$ \\
\hline
\end{tabular}

Table 6

Understanding of seminar topics in 2016-2017

\begin{tabular}{lcccccc}
\hline & & $\begin{array}{c}\text { Inclusion and } \\
\text { Bias }\end{array}$ & $\begin{array}{c}\text { Stress } \\
\text { management }\end{array}$ & $\begin{array}{c}\text { Time } \\
\text { management }\end{array}$ & $\begin{array}{c}\text { Note } \\
\text { taking }\end{array}$ & Leadership \\
\hline Strongly Agree or Agree & 14 & 14 & 15 & 9 & 5 \\
$\begin{array}{l}\text { Neither } \\
\text { Disagree }\end{array}$ & 1 & 0 & 0 & 0 & 0 \\
$\begin{array}{l}\text { Disagree } \\
\text { Disagree }\end{array}$ & & 1 & 0 & 0 & 0 & 0 \\
\hline
\end{tabular}

Table 7

Understanding of seminar topics in 2017-2018

\begin{tabular}{lccccc}
\hline & Study skills & $\begin{array}{c}\text { Stress } \\
\text { management }\end{array}$ & $\begin{array}{c}\text { Time } \\
\text { management }\end{array}$ & $\begin{array}{c}\text { Note } \\
\text { taking }\end{array}$ & Finances \\
\hline Strongly Agree or Agree & 8 & 11 & 7 & 13 & 2 \\
Neither Agree nor Disagree & 2 & 1 & 0 & 2 & 0 \\
Disagree or Strongly Disagree & 3 & 0 & 0 & 0 & 0 \\
\hline
\end{tabular}

Table 8

Understanding of seminar topics in 2018-2019

\begin{tabular}{|c|c|c|c|c|c|c|c|c|c|c|}
\hline & \multirow{2}{*}{$\begin{array}{l}\text { Study } \\
\text { skills }\end{array}$} & \multirow[t]{2}{*}{ Inclusion } & \multirow[t]{2}{*}{ Bias } & \multirow{2}{*}{$\begin{array}{c}\text { Time } \\
\text { management }\end{array}$} & \multicolumn{2}{|c|}{ Note taking } & \multicolumn{2}{|c|}{ Communication } \\
\hline & & & & & & & $\begin{array}{c}\text { During } \\
\text { class }\end{array}$ & $\begin{array}{l}\text { After } \\
\text { class }\end{array}$ & $\begin{array}{l}\text { With } \\
\text { peers }\end{array}$ & $\begin{array}{c}\text { With } \\
\text { professor }\end{array}$ \\
\hline Strongly & gree or & Agree & 8 & 12 & 12 & 8 & 5 & 6 & 6 & 4 \\
\hline $\begin{array}{l}\text { Neither } \\
\text { Disagree }\end{array}$ & Agree & e nor & 0 & 1 & 2 & 1 & 1 & 0 & 0 & 2 \\
\hline $\begin{array}{l}\text { Disagree } \\
\text { Disagree }\end{array}$ & or & Strongly & 0 & 1 & 0 & 0 & 0 & 0 & 0 & 0 \\
\hline
\end{tabular}


Table 9

Perception of professional development skill usefulness following graduation

\begin{tabular}{lcc}
\hline & URM & Non-URM \\
& $(\%)$ & 33 \\
\hline Interview skills & 67 & 25 \\
Employment after graduation & 75 & 43 \\
Personal and Professional relationships & 57 & 29 \\
Graduate Academics & 71 & 4 \\
\hline
\end{tabular}

